\title{
Atherogenic lipid profile of Brazilian near-term newborns
}

I.M.C.G. Pardo ${ }^{1}$, B. Geloneze ${ }^{2}$, M.A. Tambascia ${ }^{2}$ and A.A. Barros-Filho ${ }^{1}$
${ }^{1}$ Departamento de Pediatria, ${ }^{2}$ Departamento de Endocrinologia e Metabolismo, Faculdade de Ciências Médicas, Universidade Estadual de Campinas, Campinas, SP, Brasil

\author{
Correspondence \\ I.M.C.G. Pardo \\ Rua Souza Pereira, 138 \\ 18010-320 Sorocaba, SP \\ Brasil \\ Fax: +55-15-232-7050 \\ E-mail: doctorpardo@hotmail.com \\ Research supported by FAPESP \\ (No. 2001/04402-9). \\ $\ldots \ldots \ldots \ldots \ldots \ldots$
}

Received June 18, 2004

Accepted December 7, 2004

\begin{abstract}
Cardiovascular disease is the primary cause of death in Brazil. Recent studies have shown that low birth weight and preterm birth are linked to a higher prevalence of cardiovascular disease. The aim of the present study was to compare the levels of lipids and apolipoproteins and atherogenic indexes between term and near-term newborn infants. A sample of umbilical cord blood was obtained from 135 newborns (66 males) divided into two groups: 25 near-term neonates (35-36.6 weeks of gestational age) and 110 term neonates (37-42 weeks of gestational age). The total cholesterol concentrations were higher in the near-term neonates than in the term group (94.04 \pm 8.02 vs 70.42 $\pm 1.63 \mathrm{mg} / \mathrm{dl}, \mathrm{P}<0.01$ ), due to an increase in the LDL-cholesterol fraction in the near-term group $(57.76 \pm 6.39$ vs $34.38 \pm 1.29 \mathrm{mg} / \mathrm{dl}, \mathrm{P}$ $<0.001$ ). The atherogenic indexes (total cholesterol/HDL-cholesterol, LDL-cholesterol/HDL-cholesterol and apolipoprotein B/apolipoprotein A-I) were higher in the near-term group $(\mathrm{P}<0.001, \mathrm{P}<0.001$, and $\mathrm{P}<0.05$, respectively). The gestational age of the newborns was inversely correlated with total cholesterol and LDL-cholesterol, and also with the total cholesterol/HDL-cholesterol and LDL-cholesterol/ HDL-cholesterol indexes. These findings demonstrate that the lipid profile is worse in the group of near-term neonates compared with the term group. Future studies are needed to determine if this atherogenic profile in near-term neonates can affect body metabolism, increasing the risk for cardiovascular diseases in adult life.
\end{abstract}

\section{Introduction}

Cardiovascular disease is the primary cause of death in developed countries, as well as in Brazil and other Latin American countries (1). The incidence of coronary artery disease depends, in general, on the prevalence of genetic and environmental risk factors. Recent animal experiments and human
Key words

- Lipids

- Apolipoproteins

- Cholesterol

- Cord blood

- Cardiovascular disease

- Newborns 
hypertension may depend on strategies that promote fetal growth (4).

It is known that premature newborns have lost the chance to complete their energy deposits. Thus, many times the preterm neonate needs to use these endogenous reserves, basically activating lipid metabolism that generates energy and promotes gluconeogenesis (5). The long-term consequences of these metabolic adaptations have not been elucidated. Barker et al. (6) demonstrated that low birth weight correlated with an increased prevalence of cardiovascular disease, hypertension and type 2 diabetes mellitus. These investigators suggested that this association reflects the phenomenon known as programming, whereby a stimulation or insult during a critical period of intrauterine life could also result in alterations of physiology and metabolism during adult life (7). Apolipoprotein A-I, apolipoprotein B and the apolipoprotein B/apolipoprotein A-I ratio are considered to be markers of cardiovascular disease risk. Recent studies demonstrated that the detection of these markers in umbilical cord blood from term newborns could identify neonates at a higher risk for coronary heart disease $(8,9)$.

The aim of the present study was to compare the levels of lipids and apolipoproteins in umbilical blood cord, as well as the atherogenic indexes of term and near-term neonates.

\section{Patients and Methods}

We collected umbilical cord blood immediately after birth from 135 newborns (66 males) divided into two groups: 25 nearterm neonates (35-36.6 weeks of gestational age) and 110 term neonates (37-42 weeks of gestational age). The sample size was calculated on the basis of Campoy Folgoso et al. (5). Ninety-six samples were considered to be the minimal number required for the present study. Values of $\alpha$ and $\beta$ were established at 0.05 and 0.10 , respectively.
The newborns were selected according to the following criteria: birth weight appropriate for gestational age, gestational age between 35-42 weeks, one-minute Apgar score $>7$, absence of congenital anomalies, singleton pregnancies, and absence of maternal diseases such as hypertension, diabetes mellitus, thyroid diseases, or hypercholesterolemia. None of the mothers was taking any medication, except for vitamin and iron supplements during pregnancy. A previously tested maternal questionnaire was applied by one researcher in order to obtain maternal clinical data and information about family heart diseases. The weight and height of all pregnant women were measured and the body mass index $\left(\mathrm{kg} / \mathrm{m}^{2}\right)$ was calculated. Maternal weight gain during pregnancy was recorded. The weight, length and head circumference of all neonates were measured immediately after delivery. The newborns' weight was determined using a portable scale and length was measured using an appropriate stadiometer. Gestational age was calculated from the date of the last menstruation and confirmed by ultrasound measurement.

Umbilical venous blood was obtained at the time of delivery immediately after cord clamping and centrifuged. Serum was separated and used for the determination of total cholesterol, LDL-cholesterol and HDL-cholesterol by standard enzymatic methods (10). Apolipoprotein A-I and apolipoprotein B were measured by nephelometry (11). The following atherogenic indexes were calculated: total cholesterol/HDL-cholesterol, LDL-cholesterol/HDL-cholesterol and apolipoprotein B/apolipoprotein A-I.

The study was carried out in accordance with the current revision of the Helsinki Declaration and with Brazilian resolution 196/96. The study protocol was approved by the local Ethics Committee and written informed consent was obtained from all mothers.

Data are reported as means \pm SEM. Differences between groups were evaluated by 
the Mann-Whitney test. Spearman rank coefficients were used to determine relationships between continuous variables. A P value of less than 0.05 was considered to be significant. The SPSS Program version 7.5 was used for all statistical calculations.

\section{Results}

The clinical characteristics of the mothers of the newborns are described in Table 1. Maternal age, prepregnancy weight and weight gain during pregnancy were higher in the group who delivered at term than in the group that delivered at near-term $(\mathrm{P}=0.004$, $\mathrm{P}=0.045$, and $\mathrm{P}<0.045$, respectively). A positive family history (dyslipidemia and or heart disease) was found in $28(25.45 \%)$ of the term group and in $6(24 \%)$ of the nearterm group, with no significant difference between groups.

The characteristics of the near-term and term neonates are presented in Table 2. The near-term group had significantly lower birth weight, birth length and head circumference than the term group. No gender differences were found in cord blood total cholesterol, HDL-cholesterol, LDL-cholesterol, apolipoprotein A-I, apolipoprotein B, or atherogenic indexes (total cholesterol/HDL-cholesterol, LDL-cholesterol/HDL-cholesterol and apolipoprotein B/apolipoprotein A-I indexes). Therefore, the data were not stratified for gender.

The near-term neonate group presented a clearly different lipid profile compared to the term group, as described in Table 3. The total cholesterol concentrations were higher in the near-term group than in the term group $(94.04 \pm 8.02$ vs $70.42 \pm 1.63 \mathrm{mg} / \mathrm{dl}, \mathrm{P}<$ $0.001)$. The near-term group basically presented an increased LDL fraction compared to the term group $(57.76 \pm 6.39$ vs $34.38 \pm$ $1.29 \mathrm{mg} / \mathrm{dl}, \mathrm{P}<0.001)$. The total cholesterol/ HDL-cholesterol, LDL-cholesterol/HDLcholesterol and apolipoprotein B/apolipoprotein A-I indexes were higher in the near- term group $(\mathrm{P}<0.001, \mathrm{P}<0.001, \mathrm{P}<0.05$, respectively) compared to the term group. Although the concentrations of apolipoprotein A-I and apolipoprotein B were not significantly different, we observed a trend towards a worse lipid profile in the near-term group, with lower apolipoprotein A-I levels

Table 1. Clinical characteristics of the mothers.

\begin{tabular}{lrc}
\hline & $\begin{array}{c}\text { Term neonates } \\
(\mathrm{N}=110)\end{array}$ & $\begin{array}{c}\text { Near-term } \\
\text { neonates }(\mathrm{N}=25)\end{array}$ \\
\hline Age (years) & $25.13 \pm 0.60$ & $21.56 \pm 1.20^{*}$ \\
Weight $(\mathrm{kg})$ & $60.35 \pm 1.22$ & $55.36 \pm 1.96^{*}$ \\
Height $(\mathrm{cm})$ & $159.67 \pm 0.66$ & $159.20 \pm 1.67$ \\
BMl & $23.66 \pm 0.45$ & $21.76 \pm 0.55$ \\
Weight gain $(\mathrm{kg})$ & $11.95 \pm 0.38$ & $10.91 \pm 0.98^{*}$ \\
\hline
\end{tabular}

Data are reported as means \pm SEM. BMI = body mass index. ${ }^{*} \mathrm{P}<0.05$ compared to term neonates (Mann-Whitney test).

Table 2. Characteristics of the newborns.

\begin{tabular}{lcc}
\hline & $\begin{array}{c}\text { Term neonates } \\
(\mathrm{N}=110)\end{array}$ & $\begin{array}{c}\text { Near-term } \\
\text { neonates }(\mathrm{N}=25)\end{array}$ \\
\hline Males/females (N) & $51 / 59$ & $15 / 10$ \\
Birth weight (g) & $3181 \pm 26.99$ & $2402 \pm 71.62^{*}$ \\
Birth length (cm) & $48.41 \pm 0.14$ & $44.58 \pm 0.48^{*}$ \\
Gestational age (weeks) & $39.18 \pm 0.12$ & $35.57 \pm 0.11^{*}$ \\
Head circumference (cm) & $34.24 \pm 0.13$ & $32.02 \pm 0.32^{*}$
\end{tabular}

Data are reported as means \pm SEM

${ }^{*} \mathrm{P}<0.05$ compared to term neonates (Mann-Whitney test).

Table 3. Lipids, apolipoproteins and atherogenic indexes of the newborn umbilical cord blood.

\begin{tabular}{lrc}
\hline & $\begin{array}{c}\text { Term neonates } \\
(\mathrm{N}=110)\end{array}$ & $\begin{array}{c}\text { Near-term } \\
\text { neonates }(\mathrm{N}=25)\end{array}$ \\
\hline Total cholesterol (mg/dl) & $70.42 \pm 1.63$ & $94.04 \pm 8.02^{*}$ \\
HDL-C (mg/dl) & $26.75 \pm 0.65$ & $28.84 \pm 1.85$ \\
LDL-C (mg/dl) & $34.38 \pm 1.29$ & $57.76 \pm 6.39^{*}$ \\
Total cholesterol/HDL-C & $2.71 \pm 0.06$ & $3.26 \pm 0.13^{*}$ \\
LDL-C/HDL-C & $1.35 \pm 0.05$ & $1.97 \pm 0.12^{*}$ \\
Apo A-l (ng/dl) & $91.08 \pm 2.20$ & $89.00 \pm 5.48$ \\
Apo B (ng/dl) & $43.36 \pm 1.71$ & $56.84 \pm 7.55$ \\
Apo B/Apo A-l & $0.51 \pm 0.03$ & $0.67 \pm 0.09^{*}$ \\
\hline
\end{tabular}

Data are reported as means \pm SEM. $C=$ cholesterol; $A p o=$ apolipoprotein

${ }^{*} \mathrm{P}<0.05$ compared to term neonates (Mann-Whitney test). 
$(89.00 \pm 5.48 v s 91.08 \pm 2.20 \mathrm{ng} / \mathrm{dl})$ and higher apolipoprotein B levels than in the term neonate group $(56.84 \pm 7.55 v s 43.36 \pm$ $1.71 \mathrm{ng} / \mathrm{dl})$.

The gestational age of all 135 newborns correlated inversely with total cholesterol $(\mathrm{r}=-0.256, \mathrm{P}<0.01)$, LDL-cholesterol $(\mathrm{r}=-0.369, \mathrm{P}<0.01)$, total cholesterol/HDLcholesterol index $(r=-0.254, \mathrm{P}<0.01)$ and also with LDL-cholesterol/HDL-cholesterol index $(r=-0.351, \mathrm{P}<0.01)$ (Table 4).

\section{Discussion}

The cholesterol levels detected in umbilical cord blood were lower than those found in plasma of adults. Since total cholesterol increases after birth, it might be presumed that the total cholesterol levels of preterm neonates are similar to or lower than those observed in term infants. However, our results demonstrated that the cholesterol levels of the premature group were substantially higher than those of the term group, in agreement with a previous report (12). Moreover, our study indicates that this difference exists even though the premature neonates were near term, with a gestational age of 3536.6 weeks.

It has been reported that the plasma depletion of cholesterol that occurs at term is due to a decrease in HDL-cholesterol and LDL-cholesterol levels. Probably the cause

Table 4. Correlation coefficients between lipid profile and gestational age of 135 newborns.

Correlation coefficient

Gestational age versus Apo A-I 0.054

Gestational age versus Apo B

Gestational age versus total cholesterol*

$-0.141$

Gestational age versus HDL-C

Gestational age versus LDL-C*

$-0.256$

$-0.038$

$-0.369$

Gestational age versus Apo B/Apo A-I

$-0.081$

$-0.254$

$-0.351$ of the fall in plasma LDL-cholesterol concentration is explained by the increase of its uptake by the fetal adrenal gland for steroid hormone production, as postulated by Parker Jr. et al. (13). Since HDL-cholesterol is not metabolized efficiently by the adrenals, the fall in HDL-cholesterol levels may be associated with an increase in the activity of the lectin acetyl cholesterol transferase enzyme. Spear et al. (14) demonstrated that lectin acetyl cholesterol transferase activity was lower in near-term neonates compared with the term infants. However, we found that the decrease of total cholesterol was due to LDLcholesterol, whereas HDL-cholesterol remained constant. This finding is in agreement with the results of Parker Jr. et al. (15), but in conflict with the results of Spear et al. (14). This discrepancy might be explained by the group selected for study (very near term) or by differences in the design of the studies. Although the concentrations of apolipoprotein A-I and apolipoprotein B were not significantly different, our findings show a trend towards a worse lipid profile in the near-term group, with higher apolipoprotein B levels, related to low-density lipoproteins, and lower apolipoprotein A-I levels, related to the inverse cholesterol transport, that protect against atherosclerotic lesions. Moreover the apolipoprotein B/apolipoprotein AI index, considered to be one of the best markers of risk for cardiovascular disease even during the first year of life (16), was significantly higher in the near-term neonate group compared with the term group, demonstrating that this index is altered even in umbilical blood cord. Future studies could elucidate the reasons and the consequences of these differences between near-term and term neonates.

The gestational age of the newborns correlated inversely with total cholesterol, LDLcholesterol, and total cholesterol/HDL-cholesterol and LDL-cholesterol/HDL-cholesterol index, confirming the difference in lipid distribution between preterm and term 
infants. Preterm birth (17) and low birth weight (18) have been described as factors for cardiovascular risk in adult life. The long-term consequences of the hypercholesterolemic ambient seen in premature newborns regarding fatty streak formation are still debated. Although the atherogenic process has been recognized as a pediatric problem since 1965 , the reversibility of the injuries in this early phase of life is highly questionable. Napoli et al. (19) described aortic fatty streak formation in human fetuses, probably enhanced by maternal and presumably fetal hypercholesterolemia. A new study published by the same authors (20) demonstrated the existence of lipid accumulation in the extracranial arteries of aborted fetuses and preterm newborns, demonstrating the atherogenic response to a hypercholesterolemic environment. A twin study suggested that genetic factors account for the association of low birth weight with high levels of total cholesterol, LDL-cholesterol and apolipoprotein B (21). A recent study correlated low gestational age with abnormal retinal vascularization and increased blood pressure in adult women (22).

The results of the present study indicate the necessity for further research to determine if an adverse lipid profile can affect body metabolism, increasing the risk for future complications. This fact acquires a very important impact when we observe the high incidence of cesarean sections in Brazil, up to $81.8 \%$ in private hospitals (23), which are associated with low birth weight and preterm birth (24), reflecting often abusive indications for such procedure. A study carried out in Southeast Brazil described cesarean section as the main contributor to the increase in preterm birth rate (25), suggesting the need for reorientation in neonatal health care. Since we found changes in lipid profile in nearterm newborns, we speculate that the abusive indications of cesarean section for nearterm newborns with a birth weight of 2000$2500 \mathrm{~g}$ could be a harmful decision with metabolic consequences in later life. Research aimed at elucidating this proposition offers an important challenge to transform this situation.

Our findings demonstrate that total cholesterol, LDL-cholesterol fraction and atherogenic indexes are significantly higher in nearterm neonates compared with term infants, showing a trend to a worse lipid profile in Brazilian near-term infants. Future studies are needed to determine if this atherogenic profile in near-term neonates can affect body metabolism, increasing the risk for cardiovascular diseases in adult life.

\section{Acknowledgments}

We are grateful to the mothers and children who participated in the study.

\section{References}

1. Pramparo $P$ (2002). The epidemiology of hypertension in South America. Journal of Human Hypertension, 16: S3-S6.

2. Barker DJP (1993). The intrauterine origins of cardiovascular disease. Acta Paediatrica, 391: 93-99

3. Law CM, de Swiet M, Osmond C, Fayers PM, Barker DJ, Cruddas AM \& Fall CH (1993). Initiation of hypertension in utero and its amplification throughout life. British Medical Journal, 306: 24-27.

4. Law CM, Shiell AW, Newsome CA, Syddall HE, Shinebourne EA, Fayers PM, Martyn CN \& de Swiet M (2002). Fetal, infant, and childhood growth and adult blood pressure: a longitudinal study from birth to 22 years of age. Circulation, 105: 1088-1092.

5. Campoy Folgoso C, Bayés García R \& Molina Font J (1990). Estima- tion of the degree of metabolism-energy maturity in the premature newborn infant: plasma lipid profile and lipid transport systems. Anales Españoles de Pediatría, 33: 237-244.

6. Barker DJ, Hales CN, Fall CH, Osmond C, Phipps K \& Clark PM (1993). Type 2 (non-insulin-dependent) diabetes mellitus, hypertension and hyperlipidemia (syndrome $\mathrm{X}$ ): relation to reduced fetal growth. Diabetologia, 36: 62-67.

7. Reynolds RM \& Phillips DIW (1998). Long-term consequences of intrauterine growth retardation. Hormone Research, 49: 28-31.

8. Srintvasan S \& Berenson G (1995). Serum apolipoproteins A1 and B as markers of coronary artery disease risk early in life: The Bogalusa Heart Study. Clinical Chemistry, 41: 159-164. 
9. Casanueva V, Cid X, Chiang MT, Molina M, Ferrada MC, Perez R \& Casanueva P (1998). Serum lipids, lipoprotein and apolipoprotein levels in normal Chilean newborns. Revista Medica de Chile, 126: 1073-1078.

10. Friedwald WT, Levy RI \& Fredrickson DS (1972). Estimate of the concentration of low-density lipoprotein in plasma, without use of the preparative ultracentrifuge. Clinical Chemistry, 18: 499-502.

11. Maciejko JJ, Levinson SS, Markyvech L, Smith MP \& Blevins RD (1987). New assay of apolipoproteins A-I and B by rate nephelometry evaluated. Clinical Chemistry, 33: 2065-2069.

12. Diaz M, Leal C, Ramon y Cajal J, Jimenez MD, Martinez H, Pocovi M \& Grande F (1989). Cord blood lipoprotein-cholesterol: relationship between birth weight and gestational age of newborns. Metabolism, 38: 435-438.

13. Parker Jr CR, Simpson ER, Bilheimer DW, Leveno K, Carr BR \& MacDonald PC (1980). Inverse relation between low density lipoprotein cholesterol and dehydroisoandrosterone sulfate in human fetal plasma. Science, 208: 512-514.

14. Spear ML, Amr S, Hamosh M, Pereira GR, Corcoran LG \& Hamosh P (1991). Lecithin cholesterol acyltransferase (LCAT) activity during lipid infusion in premature infants. Journal of Pediatric Gastroenterology and Nutrition, 13: 72-76.

15. Parker Jr CR, Carr BR, Simpson ER \& MacDonald PC (1983). Decline in the concentration of low density lipoprotein cholesterol in human fetal plasma near term. Metabolism, 32: 919-923.

16. Wang XL, Wilcken DEL \& Dudman NPB (1991). Apolipoproteins A-1 and $B$ and the B/A-1 ratio in the first year of life. Pediatric Research, 30: 544-549.

17. Irving RJ, Belton NR, Elton RA \& Walker BR (2000). Adult cardiovascular risk factors in premature babies. Lancet, 355: 2135-2136.

18. Lindsay RS, Dabelea D, Roumain J, Hanson RL, Bennett $\mathrm{PH}$ \& Knowler WC (2000). Type 2 diabetes and low birth weight: the role of paternal inheritance in the association of low birth weight and diabetes. Diabetes, 49: 445-449.
19. Napoli C, D'Armiento FP, Mancini FP, Postiglione A, Witztum JL, Palumbo G \& Palinski W (1997). Fatty streak formation occurs in human fetal aortas and is greatly enhanced by maternal hypercholesterolemia: intimal accumulation of LDL and its oxidation precede monocyte recruitment into early atherosclerotic lesions. Journal of Clinical Investigation, 100: 2680-2690.

20. Napoli C, Witztum JL, de Nigris F, Palumbo G, D'Armiento FP \& Palinski W (1999). Intracranial arteries of human fetuses are more resistant to hypercholesterolemia-induced fatty streak formation than extracranial arteries. Circulation, 99: 2003-2010.

21. Ijzerman RG, Stehouwer CD, Van Weissenbruch MM, De Geus EJ \& Boomsma DI (2001). Evidence for genetic factors explaining the association between birth weight and low-density lipoprotein cholesterol and possible intrauterine factors influencing the association between birth weight and high-density lipoprotein cholesterol: analysis in twins. Journal of Clinical Endocrinology and Metabolism, 86: 5479-5484.

22. Kistner A, Jacobson L, Jacobson SH, Svensson E \& Hellstrom A (2002). Low gestational age associated with abnormal retinal vascularization and increased blood pressure in adult women. Pediatric Research, 51: 675-680.

23. Yazlle ME, Rocha JS, Mendes MC, Patta MC, Marcolin AC \& de Azevedo GD (2001). Incidence of cesarean delivery regarding the financial support source for delivery care. Revista de Saúde Pública, 35: 202-206.

24. Silva AA, Lamy-Filho F, Alves MT, Coimbra LC, Bettiol H \& Barbieri MA (2001). Risk factors for low birthweight in north-east Brazil: the role of caesarean section. Paediatric and Perinatal Epidemiology, 15: 257-264.

25. Bettiol H, Rona RJ, Chinn S, Goldani M \& Barbieri MA (2000). Factors associated with preterm births in southeast Brazil: a comparison of two birth cohorts born 15 years apart. Paediatric and Perinatal Epidemiology, 14: 30-38. 